\title{
Extraction of Tooth
}

National Cancer Institute

\section{Source}

National Cancer Institute. Extraction of Tooth. NCI Thesaurus. Code C51770.

The surgical removal of a tooth from its bony socket. 